\title{
The Use of Bring Your Own Device-based Learning to Measure Student Algebraic Thinking Ability
}

\author{
https://doi.org/10.3991/ijet.v14i23.11050
Hendra Erik Rudyanto $(\bowtie)$, Marsigit, Muhammad Nur Wangid
Universitas Negeri Yogyakarta, Yogyakarta, Indonesia
hendra.erik2016estudent.uny.ac.id \\ Sardulo Gembong \\ Universitas PGRI Madiun, Madiun, Indonesia
}

\begin{abstract}
Many elementary students have algebraic difficulties in learning. This is proven by the fact that elementary students having difficulty facing algebraic material, where they lack the ability to solve algebraic problems called algebraic thinking skills. This study focuses on finding out the judgment of experts about the use of BYOD-based mathematics knowledge to measure elementary students' algebraic completion skills. This research applied 3 tests in the control class and treatment class with the reliability of Cronbach to see an increase in the use of BYOD-based learning. Thus, there is an increase in the use of BYOD-based learning to measure students' algebraic thinking abilities.
\end{abstract}

Keywords - Online learning systems, teaching skills, seesaw class

\section{Introduction}

For many years, Algebra teaching and learning have been consistently categorized as one of the leading research fields in mathematics education. Recently, research on early algebra has gained increased interest [1]-[6]. Some of the main initial ideas behind the early algebra movement were to determine: (a) whether elementary students can really start learning algebra [7] and (b) if the initial exposure to basic algebraic concepts can alleviate the very difficulties that adolescents face in algebra in secondary education [8].

Many elementary students experience algebraic difficulties in learning. This difficulty is known because they faced difficulties with algebraic material in mathematics class. Students lack the ability to solve algebraic problems called algebraic thinking skills. The ability to describe relationships and settlement procedures, and the techniques involved in the general way, are important features of algebraic thinking so that extending the name 'algebra' as long as no other name is proposed [9].

Algebra learning difficulties can be anticipated by using mobile learning to overcome these problems and it is relevant to the era of the industrial revolution 4.0. In this 21st era, learning algebra often uses GeoGebra applications and the like [10]. The use of the application is only to explain one material in one meeting, but there are 
applications that can be used in one semester as well as the teacher and students can enter into the online class so that interactions can occur in the application.

The recognition that education must adapt to technological changes in the wider community is a factor in the development of BYOD [11]. Because the use of digital devices every day by elementary school students is increasing, so is the need for schools to integrate digital technology to remain relevant [12], [13]. Your own devicecarrying phenomenon (BYOD), which starts at school, finds its way to K-12 classrooms. BYOD only means a policy that allows students to bring privately owned mobile devices (laptops, tablets, and smartphones) to school, and use these devices to access special learning information and applications [14].

In modern American classrooms, teachers face the monumental task of taking large heterogeneous groups of students from each of their unique starting points to test success in less than 10 months [15]. Teachers must not only identify the strengths and weaknesses of each student, but they must also distinguish instructions and support to reflect those findings. Knowre, an online learning program for middle and high school math classes, has the ability to make this task complete, so can be possible to be applied at the elementary school level.

The following discussion explores Knowre through the lens of research that is encouraged in the main areas of Feedback for Students, Student Support, and Feedback for Teachers. These three fields are closely related to student achievement and are very important for Knowre's content development and technology. The use of math knowre can be classified into bring your own device-based learning because students use their own devices in the classroom for the learning process. There are a number of different approaches that can be used to investigate the use of digital devices in the classroom. This is like Amir et. al who use augmented reality-based learning media to improve the spatial abilities of elementary students [10], [16].

Therefore, this study focuses on finding out how experts assess the use of BYODbased mathematics knowledge to measure students' algebraic completion skills.

\section{Methods}

This study was designed and conducted as a pre-test post-test with experimental control class design to determine how to use knowre mat, which is BYOD-based learning, in improving student algebraic abilities. In this study, the dependent variable is the ability of students to understand algebra and the independent variable is an activity carried out using the knowre math application which is BYOD-based learning. This research carried out 10 meetings with 3 tests, namely pre-test, middle test, and post-test from elementary students as the subject of this research. Each question refers to 3 activities of algebraic thinking abilities, namely generalization, transformational, and global meta-levels of 8 sub-activity. The estimated reliability of the test was calculated using Cronbach's alpha, obtaining a value of 0.78. Cronbach's alpha coefficient: $0.9>$ very good; $0.8>$ good; $0.7>$ accepted; $0.6>$ questionable and $0.5>$ low [17]. 


\section{$3 \quad$ Results and Discussions}

\subsection{Online learning systems through seesaw class}

Knowre is an educational technology company with innovative cloud-based adaptive learning programs for elementary school. Knowre assesses students' strengths and weaknesses create a personalized curriculum that targets individual gaps in learning algorithmically and engages students through polarized learning and beautiful graphics. Through the Teacher Dashboard, Knowre provides data to the teacher about the progress of each student and highlights where individuals, or the whole class, might struggle.

Knowre's flexibility allows schools to use the program in a variety of ways, from the core to additions, from remediation to enrichment. Knowre's vision is to provide the most effective education by systematizing world knowledge and personalizing learning experiences for students around the world. The ability to provide specific and real-time student information for teachers is an important component of Knowre. When equipped with continuous data, the teacher can lead learning, rather than just reacting to summative evidence from the learning, an approach that is the key to effectiveness [18].

The data provided to the teacher on their Teacher Dashboard is based on the information value of Formative Assessment. Formative assessment is a category of assessment that occurs repeatedly during learning to identify student misunderstandings and learning gaps to inform the next step. This type of assessment is different from the more general Summative Assessment, which evaluates a student at the end of the study program, captures their achievements and knowledge at a certain point in time, to determine mastery.

On the Teacher's Dashboard, the teacher can see student achievements in real-time at the level of learning, skills, and sub-skills. With this information, teachers can work with students in a very focused manner during the class period. When Knowre is finished for homework, the teacher can see progress on their Dashboard and use the information to inform the next day's lesson. All data on the Teacher's Dashboard is easily managed and accessed during the school year, making it a good resource for notifying standard exam preparation and teaching again at any time. 


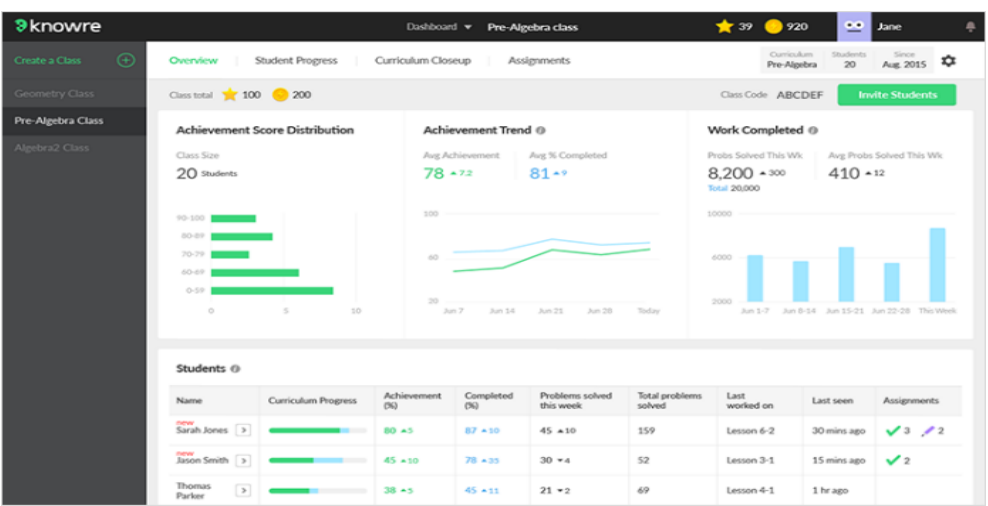

Fig. 1. Student value dashboard for teachers

Because students are also constantly aware of what they are doing, teachers can easily have data-driven specific conversations with students. Through this facilitated conversation, students can be empowered to monitor and criticize their own learning, a process that increases the effectiveness of formative assessment data for students and makes the learning process less teacher-driven and more collaborative [19]

The responses that students enter in WMT fulfill three main functions. First, they allow programs to examine understanding and determine what skills or topics are causing problems as a teacher would. Data obtained in the examination is transferred to the teacher in real-time. Second, they provide opportunities for students to overcome previous knowledge gaps by practicing the skills needed. Finally, the active involvement of students in WMT makes them involved in the learning process.

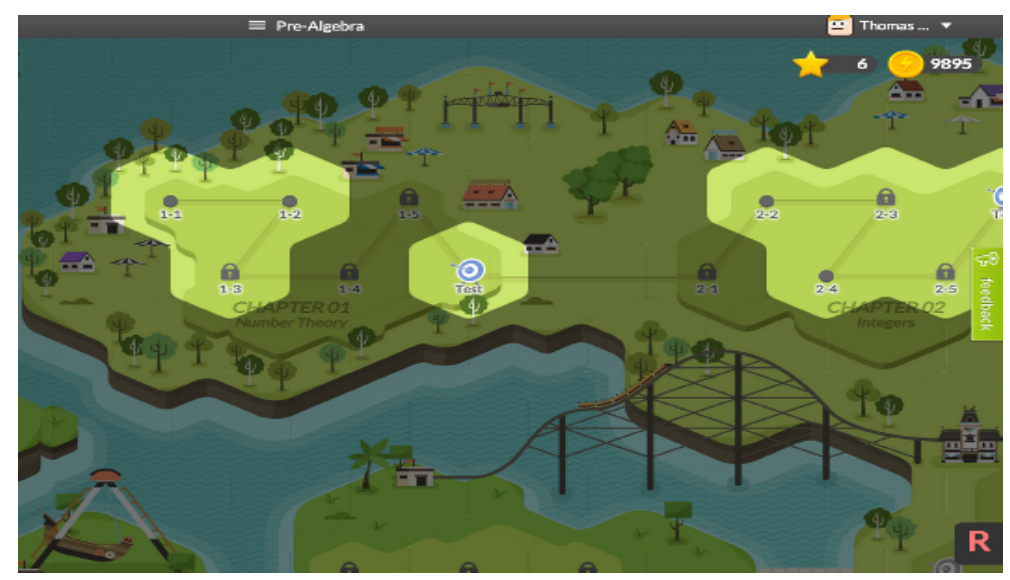

Fig. 2. Map of student activities

Knowre also allows teachers to work more deliberately and effectively. This is achieved through technology that automates the collection of formative assessment data, while simultaneously providing that data to teachers and students. Equipped 
with data, the teacher can easily create small groups and differentiate their instructions to meet the unique learning gap of students.

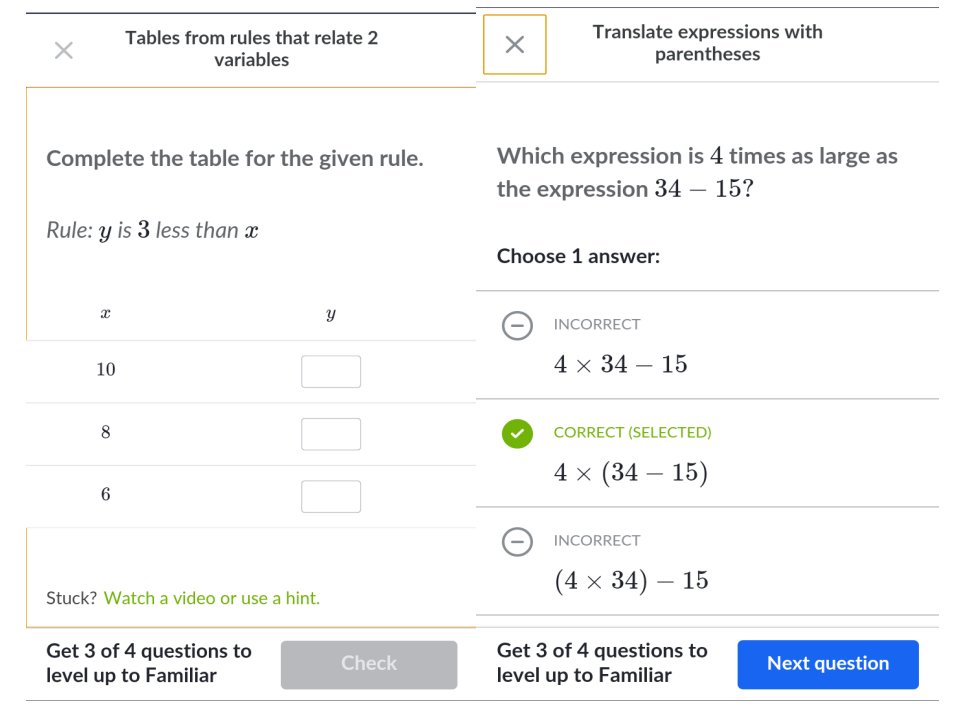

Fig. 3. Example question from knower about algebraic thinking

The question that shown from figure 3 is about algebraic thinking for elementary students. The first question is about the tables from rules that relate 2 variables and the second question is about to translate expression with parentheses. From this question, the student can increase their generalizing and transformational step from algebraic thinking.

At the earliest grades, young children work with patterns. At an early age, the student has a natural love of mathematics, and their curiosity is a strong motivator as they try to describe and extend patterns of shapes, colors, sounds, and eventually letters and numbers [20]. At a young age, students can begin to make generalizations about patterns that seem to be the same of different. This kind of categorizing and generalizing is an important development step on the journey toward algebraic thinking. At the moment, Knowre provide contents for Pre-Algebra, Algebra I, Algebra II and Geometry (Beta), and provide partial product demo one-by-one based on demand. 


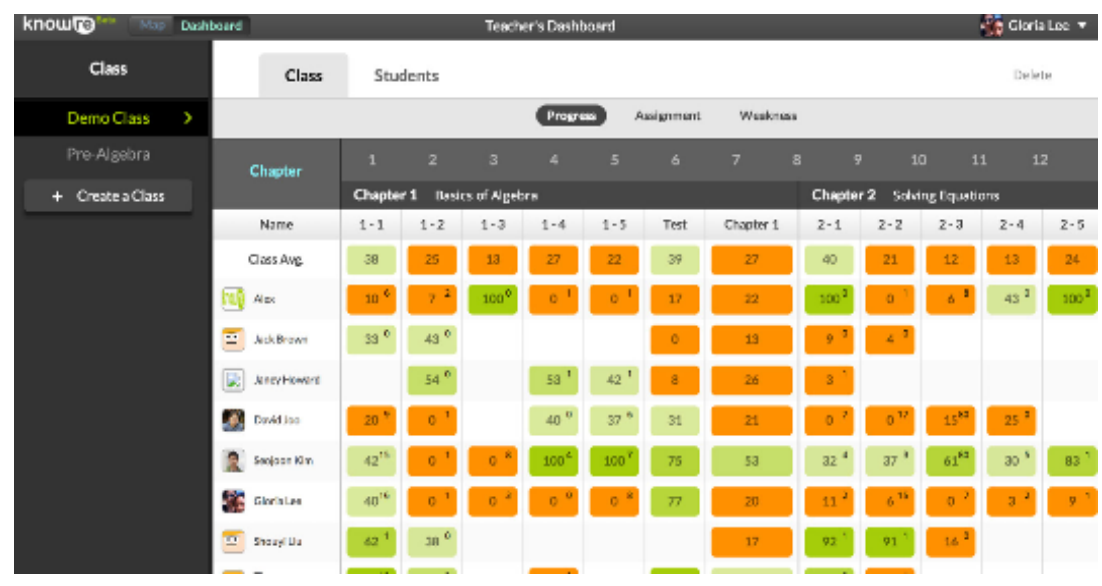

Fig. 4. Value data achieved by students

\subsection{The result of students'basic teaching skills}

Algebraic thinking skills tests range from 0 to 80 points because each of the five questions per activity can receive a score of 0 to 2 for each of the 8 activities analyzed. This means that a student can get from 0 to 10 points in each of his activities.

Table 1. Results of algebraic thinking skills' treatment group

\begin{tabular}{|l|c|c|c|}
\hline \multicolumn{1}{|c|}{ Activity } & $\begin{array}{c}\text { Pre-Test Mean Score } \\
\text { (St. D) }\end{array}$ & $\begin{array}{c}\text { Middle Test Mean Score } \\
\text { (St. D) }\end{array}$ & $\begin{array}{c}\text { Post Test Mean Score } \\
\text { (St. D) }\end{array}$ \\
\hline Generalization 1 & $5,12(0,99)$ & $6,02(1,18)$ & $7,68(1,0)$ \\
\hline Generalization 2 & $5,29(1,04)$ & $6,51(1,08)$ & $7,68(1,33)$ \\
\hline Tranformational 1 & $5,72(1,26)$ & $6,68(1,06)$ & $7,97(0,79)$ \\
\hline Tranformational 2 & $5,55(1,13)$ & $6,78(0,97)$ & $6,78(0,97)$ \\
\hline Tranformational 3 & $5,21(1,30)$ & $6,31(0,86)$ & $6,68(0,93)$ \\
\hline Meta-level Global 1 & $5,29(1,14)$ & $5,65(1,18)$ & $6(1,36)$ \\
\hline Meta-level Global 2 & $4,95(1,1)$ & $5,78(0,88)$ & $6,14(0,85)$ \\
\hline Meta-level Global 3 & $5,31(1,38)$ & $6,48(0,95)$ & $6,78(0,91)$ \\
\hline MEAN & 5,305 & 6,276 & 6,963 \\
\hline
\end{tabular}

Table 1 shows the results for the component of the Algebraic thinking of the treatment group. This shows a graph of the increase in each algebraic thinking activity that has a significant increase and is the same for each activity. Meanwhile, the control group is different from the treatment group, which shows a minimal increase and a decline occurs. This increase and decrease also occur with the value of students being low compared to the treatment group. Table 2 explains the value of the control group. 
Table 2. Results of algebraic thinking skills' control group

\begin{tabular}{|l|c|c|c|}
\hline \multicolumn{1}{|c|}{ Activity } & $\begin{array}{c}\text { Pre-Test Mean Score } \\
\text { (St. D) }\end{array}$ & $\begin{array}{c}\text { Middle Test Mean Score } \\
\text { (St. D) }\end{array}$ & $\begin{array}{c}\text { Post Test Mean Score } \\
\text { (St. D) }\end{array}$ \\
\hline Generalization 1 & $5,08(0,91)$ & $5,11(1,1)$ & $5,58(0,91)$ \\
\hline Generalization 2 & $4,66(1,06)$ & $4,43(0,98)$ & $4,64(0,85)$ \\
\hline Tranformational 1 & $4,56(1,38)$ & $5,33(1,13)$ & $5,87(1,36)$ \\
\hline Transformational 2 & $3,55(0,99)$ & $3,47(0,79)$ & $3,56(0,86)$ \\
\hline Transformational 3 & $5,12(0,87)$ & $5,42(0,80)$ & $5,74(0,95)$ \\
\hline Meta-level Global 1 & $4,98(0,87)$ & $5,03(1,09)$ & $5,67(0,77)$ \\
\hline Meta-level Global 2 & $3,95(1,13)$ & $4,51(0,77)$ & $5,08(1,03)$ \\
\hline Meta-level Global 3 & $4,61(1,03)$ & $5,45(0,85)$ & $5,74(0,89)$ \\
\hline Mean & 4,563 & 4,843 & 5,238 \\
\hline
\end{tabular}

Thus, it can be said that there is an overall increase in algebraic thinking abilities. The results of the control group in the algebraic thinking score test confirmed that students did not participate in the use of math knowledge to measure students' algebraic thinking skills.

\subsection{Discussion}

Based on the analysis, it can be seen that learning media based on Bring Your Own Device (BYOD) through the application of math knowre can improve students' algebraic thinking skills. Because with the presence of BYOD this provides easy access between students and teachers who teach. The business benefits of having access to any time, anywhere employees, blurring the work - leisure divide and saving costs by having employees purchase their preferred devices rather than providing devices out of the corporate budget [21].

Algebraic thinking can be interpreted as an approach to quantitive situations that emphasized the general relational aspects with tools that are not necessarily lettersymbolic, but which can ultimately be used as cognitive support for the introduction and for sustainable the more traditional discourse of school algebra [22]-[24]. The development of algebraic thinking is a process, not an event so there are somethings that can be positive to increase elementary student's algebraic thinking. The potential value of this strategy is proven by an increase during the course of learning by being given a pretest, middle test, and post-test to students to find out how much improvement in students' algebraic thinking skills with three main activities.

BYOD media-based learning through Knowre Math enhances students' algebraic thinking skills. In the treatment group, there were differences in mean scores that were statistically significant between pretest 5.12 and post-test to 7.68 out of 10 in the Algebraic Thinking Test. Students practice their algebraic thinking skills by completing each sub-activity in the application which is monitored directly by the teacher who is tearful, analyzing the results of algebraic thinking activities, all activities show a statistically significant increase except for transformational activities 2 . The results of the control group in the algebraic thinking test confirmed that students who did not 
participate in the use of BYOD-based learning media through Knowre Math to measure algebraic thinking skills.

\section{Conclusion}

The results of this study showed a statistically significant increase between the control class and the treatment class. With the results of the average treatment class score 5,305 for the pre-test, 6,276 for the middle test and 6,963 for the post-test, it can be seen that there was a significant increase from the pretest to the middle test. Meanwhile, the average control class was 4.563 for the pretest, 4.843 for the middle test, and 5.238 for the post-test so that it can be seen that there was no significant increase because the score of students was only 4-5, half of the maximum score on one point.

\section{$5 \quad$ References}

[1] J. Ainley, "Doing algebra-type stuff: Emergent algebra in the primary school," in Proceedings of the 23rd Annual Conference of the International Group for the Psychology of Mathematics Education, 1999, pp. 9-16.

[2] J. Cai and E. Knuth, Early algebraization. New York: Springer Science \& Business Media, 2011.

[3] J. J. Kaput, "Transforming algebra from an engine of inequity to an engine of mathematical power by 'algebrafying' the K-12 curriculum," in The nature and role of algebra in the K-14 curriculum: Proceedings of a national symposium, 1998.

[4] J. J. Kaput, M. Blanton, and L. Moreno, "Algebra from a symbolization point of view," in Algebra in the early grades, J. J. Kaput, D. W. Carraher, and M. L. Blanton, Eds. New York: Routledge, 2008, pp. 19-55. https://doi.org/10.4324/9781315097435-3

[5] F. D. Rivera, "Second grade students' preinstructional competence in patterning activity," in Proceedings of the 34th Conference of the International Group for the Psychology of Mathematics Education, 2010, pp. 81-88.

[6] R. Vergel, "Pattern generalization and forms of early algebraic thinking," PNA, vol. 9, no. 3, pp. 193-215, 2015.

[7] D. W. Carraher and A. Schliemann, "Early algebra and algebraic reasoning," in Second handbook of research on mathematics teaching and learning, F. K. Lester, Ed. Greenwich: Information Age Publishing, 2007, pp. 669-705.

[8] M. Blanton, B. Brizuela, A. Gardiner, K. Sawrey, and A. Newman-Owens, "A progression in first-grade children's thinking about variable and variable notation in functional relationships," Educ. Stud. Math. Online First, 2017. https://doi.org/10.1007/s10649-016$\underline{9745-0}$

[9] K. R. Koedinger and A. Terao, "A Cognitive Task Analysis of Using Pictures To Support Pre-Algebraic Reasoning," 2003.

[10] M. F. Amir, C. Chotimah, R. Afandi, H. E. Rudyanto, and I. Anshori, "Design Research Study: Investigation of Increasing Elementary Student's Spatial Ability Using 3Dmetric,” J. Adv. Res. Dyn. Control Syst., vol. 10, no. 6, pp. 1707-1713, 2018. https:// doi.org/10.31227/osf.io/6fbzi 
[11] M. Olalere, M. T. Abdullah, and R. Mahmod, "A Review of Bring Your Own Device on Security Issues,” SAGE Open, no. April, pp. 1-11, 2015. https://doi.org/10.1177/21582440 $\underline{15580372}$

[12] C. Engelhard and K. Kyeong-Ju Seo, "Going from Obsolete to Innovative: Empowering Problem-Based Learning with Online Social Media," in Designing Problem-Driven Instruction with Online Social Media, Information Age Publishing, K. Kyeong-Ju Seo, D. A. Pellegrino, and . Engelhard, Eds. Charlotte, 2012.

[13] B. Collis and J. Moonen, "Web 2.0 Tools and Processes in Higher Education: Quality Perspectives,” EMI. Educ. Media Int., vol. 45, no. 2, pp. 93-106, 2008. https://doi.org/10.10 $\underline{\text { 80/09523980802107179 }}$

[14] E. Vairaktaris, C. Demakos, and G. Metaxas, "Geometry in structural mechanics education revisited,” World Trans. Eng. Technol. Educ., vol. 11, no. 3, pp. 163-168, 2013.

[15] K. An, O. Math, and P. Rooted, "Knowre through a research lens," pp. 1-9.

[16] M. F. Amir, N. Fediyanto, C. Chotimah, and H. E. Rudiyanto, "Developing 3Dmetric Media Prototype through a Hypothetical Learning Trajector to Train Students Spatial Skill," J. Adv. Res. Dyn. Control Syst., vol. 10, no. 02-Special Issue, pp. 1537-1542, 2018. https:// doi.org/10.31227/osf.io/vmk45

[17] D. George and M. Mallery, SPSS for Windows step by step: a simple guide and reference. Boston: Allyn \& Bacon, 2003. https://doi.org/10.4324/9781351033909

[18] NCTM, "Why is Teaching with Problem Solving Important to Student Learning?," Natl. Counc. Teach. Math., vol. 13, no. 12, pp. 1-6, 2010.

[19] S. Wismath, D. Orr, and M. Zhong, "Student Perception of Problem Solving Skills," Transform. Dialogues Teach. Learn. J., vol. 7, no. 3, pp. 1-18, 2014.

[20] C. Seeley, "A Journey in Algebraic Thinking," National Council of Teachers of Mathematics, Sep-2004.

[21] V. Font, J. Godino, and J. Gallardo, "The emergence of objects from mathematical practices,” Educ. Stud. Math., vol. 82, pp. 97-124, 2013. https://doi.org/10.1007/s10649-012$\underline{9411-0}$

[22] C. Kieran, "Algebraic Thinking in the Early Grades: What Is It?," Math. Educ., vol. 8, no. 1, pp. 139-151, 2004.

[23] S. Alejandre, “Developing Algebraic Thinking,” Natl. Counc. Teach. Math., 2002.

[24] J. Schmittau, "The Development of Algebraic Thinking - A Vygotskian Perspective," Anal. ZDM, vol. 37, no. 1, 2005.

\section{Authors}

Hendra Erik Rudyanto, Primary Education, Graduate School, Universitas Negeri Yogyakarta, Yogyakarta, Indonesia

Marsigit, Primary Education, Graduate School, Universitas Negeri Yogyakarta, Indonesia

Muhammad Nur Wangid, Primary Education, Graduate School, Universitas Negeri Yogyakarta, Indonesia

Sardulo Gembong, Mathematics Education Department, Universitas PGRI Madiun, Madiun, Indonesia.

Article submitted 2019-06-26. Resubmitted 2019-08-09. Final acceptance 2019-08-12. Final version published as submitted by the authors. 